Karen Anthony, PhD*

Virginia ArechavalaGomeza, PhD*

Laura E. Taylor, BS

Adeline Vulin, PhD

Yuuki Kaminoh, BS

Silvia Torelli, PhD

Lucy Feng, PhD

Narinder Janghra, BSc

Gisèle Bonne, PhD

Maud Beuvin, MS

Rita Barresi, PhD

Matt Henderson, MSc

Steven Laval, PhD

Afrodite Lourbakos, $\mathrm{PhD}$

Giles Campion, MD

Volker Straub, MD

Thomas Voit, MD

Caroline A. Sewry, PhD

Jennifer E. Morgan, PhD

Kevin M. Flanigan, MD

Francesco Muntoni, $\mathrm{MD} \ddagger$

Correspondence to

Prof. Muntoni:

f.muntoni@ucl.ac.uk

Supplemental data at Neurology.org

\title{
Dystrophin quantification
}

\section{Biological and translational research implications OPEN}

\section{ABSTRACT}

Objective: We formed a multi-institution collaboration in order to compare dystrophin quantification methods, reach a consensus on the most reliable method, and report its biological significance in the context of clinical trials.

Methods: Five laboratories with expertise in dystrophin quantification performed a data-driven comparative analysis of a single reference set of normal and dystrophinopathy muscle biopsies using quantitative immunohistochemistry and Western blotting. We developed standardized protocols and assessed inter- and intralaboratory variability over a wide range of dystrophin expression levels.

Results: Results from the different laboratories were highly concordant with minimal inter- and intralaboratory variability, particularly with quantitative immunohistochemistry. There was a good level of agreement between data generated by immunohistochemistry and Western blotting, although immunohistochemistry was more sensitive. Furthermore, mean dystrophin levels determined by alternative quantitative immunohistochemistry methods were highly comparable.

Conclusions: Considering the biological function of dystrophin at the sarcolemma, our data indicate that the combined use of quantitative immunohistochemistry and Western blotting are reliable biochemical outcome measures for Duchenne muscular dystrophy clinical trials, and that standardized protocols can be comparable between competent laboratories. The methodology validated in our study will facilitate the development of experimental therapies focused on dystrophin production and their regulatory approval. Neurology ${ }^{\circledR}$ 2014;83:2062-2069

\section{GLOSSARY}

BMD = Becker muscular dystrophy; BOM-SG = biochemical outcome measures study group; $\mathbf{C V}$ = coefficient of variation; DMD = Duchenne muscular dystrophy; IgG = immunoglobulin G; PBS = phosphate-buffered saline.

Duchenne muscular dystrophy (DMD) is an X-linked neuromuscular disorder caused by mutations in the $D M D$ gene, which prevent the expression of its product, dystrophin. ${ }^{1,2}$ The milder Becker muscular dystrophy (BMD) is also caused by $D M D$ mutations that result in variable expression of a shorter dystrophin. ${ }^{1-5}$ Therapeutic interventions aimed at restoring dystrophin expression are in clinical trials. ${ }^{6-14}$ Dystrophin quantification is an essential biochemical outcome measure for these trials. However, the absence of a reference standard, the large size and low expression of the protein, combined with preexisting dystrophin-positive revertant fibers and residual trace dystrophin, ${ }^{15}$ make accurate quantification challenging, especially when the amount of restored dystrophin is small. ${ }^{15,16}$ Because regulatory authorities previously indicated that lack of consensus on the standardized methodology was an obstacle to the advancement of the field, ${ }^{17}$ a group of laboratories from academia and industry formed a biochemical outcome

\footnotetext{
*These authors contributed equally to this work.

$\ddagger$ These authors contributed equally to this work.

From The Dubowitz Neuromuscular Centre (K.A., V.A.-G., S.T., L.F., N.J., C.A.S., J.E.M., F.M.), UCL, Institute of Child Health, London, UK; The Center for Gene Therapy (L.E.T., A.V., Y.K., K.M.F.), The Research Institute at Nationwide Children's Hospital, Columbus, OH; Institut de Myologie (G.B., M.B., T.V.), UPMC UM76, INSERM U 794, CNRS UMR 7215, Paris, France; Institute of Genetic Medicine (R.B., M.H., S.L., V.S.), Newcastle University, UK; and Prosensa Therapeutics (A.L., G.C.), Leiden, the Netherlands. V.A.-G. is currently affiliated with the Neuromuscular Disorders Group, BioCruces Health Research Institute, Barakaldo, Spain.

Go to Neurology.org for full disclosures. Funding information and disclosures deemed relevant by the authors, if any, are provided at the end of the article. The Article Processing Charge was paid by the UCL Open Access grant scheme.

This is an open access article distributed under the Creative Commons Attribution License, which permits unrestricted use, distribution, and reproduction in any medium, provided the original work is properly cited.
} 
measures study group (BOM-SG) to provide a data-driven reproducible methodology for dystrophin quantification. In a pilot study comparing the sensitivity and reliability of the preferred individual laboratories' methodologies, we found significant levels of interand intralaboratory variability (data not shown). Herein, we present a controlled analysis of proposed standard operating procedures for quantitative immunohistochemistry and Western blotting for evaluation of dystrophin expression. We discuss the biological significance of our data in the context of dystrophic muscle pathology. We demonstrate that data from different laboratories can be comparable, thus validating immunohistochemistry and Western blotting as biochemical biomarkers for DMD clinical trials.

METHODS Five laboratories of the BOM-SG (The Dubowitz Neuromuscular Centre, UCL Institute of Child Health, London, UK; the Flanigan laboratory at the Center for Gene Therapy, Nationwide Children's Hospital, Columbus, $\mathrm{OH}$; Institute of Genetic Medicine, Newcastle University, UK; Institut de Myologie, UPMC UM76, INSERM U 794, CNRS UMR 7215, Paris, France; and Prosensa Therapeutics, Leiden, the Netherlands) performed blinded analysis of the same set of muscle biopsies (control [ $\mathrm{n}=2]$, DMD [ $\mathrm{n}=3]$, and BMD $[\mathrm{n}=3]$ ) (table 1) using standardized immunohistochemistry and Western blotting protocols.

Standard protocol approvals, registrations, and patient consents. We obtained written informed consent for the use of archived muscle tissues from all patients or guardians (as appropriate) under a protocol approved by the Nationwide Children's Hospital institutional review board. The studies at Great Ormond Street Hospital were performed under approval by the National Research Ethics Committee (05/MRE12/32).

Muscle biopsies. We selected muscle biopsies previously archived as part of the United Dystrophinopathy Project in the Flanigan laboratory. All biopsies had been assessed for dystrophin content on a clinical or research basis and were dispensed labeled only with a blinded code, maintained in the Flanigan laboratory. ${ }^{18}$ Each laboratory received the same number of unfixed frozen serial $10-\mu \mathrm{m}$ transverse muscle sections on microscope slides and an Eppendorf tube containing forty $10-\mu \mathrm{m}$ sections of frozen muscle tissue. All laboratories were informed of the identity of the control biopsies.

Immunohistochemistry. The staining protocol, based on that of Taylor et al., ${ }^{18}$ was as follows:

- Transverse sections were air-dried at room temperature for 20 to 30 minutes and circled with a hydrophobic peroxidase-antiperoxidase pen.

- Primary dystrophin (rabbit C-terminal ab15277; Abcam, Cambridge, MA) and spectrin (monoclonal NCL-SPEC1; Leica Microsystems Inc., Buffalo Grove, IL) antibodies were diluted (1:400 and 1:100, respectively) in phosphate-buffered saline (PBS) and incubated with the sections for 1 hour at room temperature.

- Sections were washed $(3 \times)$ in PBS for 3 minutes each.

- Each laboratory used secondary antibodies compatible with their microscope, e.g., Alexa Fluor 488 goat anti-mouse immunoglobulin G (IgG) (A11017; Molecular Probes, Eugene, OR) and Alexa Fluor 568 goat anti-rabbit IgG (A11036; Molecular Probes). These were diluted 1:500 in PBS and incubated for 30 minutes in the dark at room temperature.

- Sections were washed $(3 \times)$ in PBS for 3 minutes.

- Slides were mounted using anti-fade mounting agent, e.g., ProLong Gold anti-fade reagent (Molecular Probes).

All laboratories measured dystrophin intensity using the Arechavala-Gomeza method, which measures the fluorescent intensity of 40 specific sarcolemmal regions of interest ${ }^{19}$ selected manually at random. Each of these regions of interest includes maximum and minimum intensity data points that are used in the data analysis. In parallel, 3 laboratories (1, 4, and 5) also quantified dystrophin using the Taylor method. ${ }^{18}$ This method makes use of the double staining with spectrin, another sarcolemmal protein whose level is unaffected in dystrophinopathy muscle, to create a mask that defines only the sarcolemmal area in each image. This mask allows the measurement of the intensity of the sarcolemmal area of the whole image. ${ }^{18}$ In addition, laboratory 4 used the Beekman method in which a spectrin mask is also used to select the sarcolemma of each individual fiber of the image. ${ }^{20}$ With this algorithm, the individual intensities of an average of 350 fibers are measured and the mean dystrophin intensity of the fiber population is calculated using Definiens

Table 1 Sample ranking order by laboratory

Immunohistochemistry

\begin{tabular}{llllll}
\hline Sample & Lab 1 & Lab 2 & Lab 3 & Lab 4 & Lab 5 \\
A (BMD) & 1 & 1 & 1 & 1 & 2 \\
F (BMD) & 2 & 2 & 2 & 2 & 1 \\
D (BMD) & 3 & 3 & 3 & 3 & 3 \\
C (DMD) & 4 & 4 & 4 & 4 & 4 \\
E (DMD) & 5 & 6 & 6 & 5 & 5 \\
B (DMD) & 6 & 5 & 5 & 6 & 6
\end{tabular}

\begin{tabular}{llllll}
\multicolumn{1}{l}{ Western blotting } \\
\hline Sample & Lab 1 & Lab 2 & Lab 3 & Lab 4 & Lab 5 \\
F (BMD) & 1 & 1 & 1 & 1 & 1 \\
D (BMD) & 2 & 3 & 2 & 3 & 2 \\
A (BMD) & 3 & 2 & 3 & 2 & 3 \\
C (DMD) & 4 & 4 & 4 & 4 & 4 \\
E (DMD) & $5 / 6$ & $5 / 6$ & 5 & 5 & $5 / 6$ \\
B (DMD) & $5 / 6$ & $5 / 6$ & 6 & 6 & $5 / 6$
\end{tabular}

Abbreviations: $\mathrm{BMD}=$ Becker muscular dystrophy; del = deletion; $\mathrm{DMD}=$ Duchenne muscular dystrophy; dup = duplication; ex = exon. Samples: $\mathrm{A}=\mathrm{c} .40 .41$ delGA; $\mathrm{B}=$ dup ex $10-17 ; \mathrm{C}=\operatorname{dup}$ ex $7 ; \mathrm{D}=\operatorname{del}$ ex 3-27; $\mathrm{E}=\operatorname{del}$ ex 6; $\mathrm{F}=$ del ex 10-44. 
software. ${ }^{20}$ The key difference between these methods relates to the number of fibers measured per captured image. For a detailed protocol of each method, see e-Methods on the Neurology ${ }^{\circledR}$ Web site at Neurology.org.

Western blotting. The protocol, based on that of Taylor et al., ${ }^{18}$ was as follows:

- Samples were solubilized in lysis buffer (4.4 mM Tris, 9\% sodium dodecyl sulfate, $4 \%$ glycerol, $5 \% \beta$-mercaptoethanol).

- Loading $25 \mu \mathrm{g}$ of protein, each laboratory used their preferred gel electrophoresis (typically 3\%-8\% tris-acetate gradient gels) and Western blotting equipment.

- Membranes were incubated with the anti-dystrophin primary antibody (ab15277) at $1 \mu \mathrm{g} / \mathrm{mL}$ overnight at $4^{\circ} \mathrm{C}$ in 5\% milk TBS-T (TRIS buffered saline, 0.1\% Tween20).

- A sarcomeric $\alpha$-actinin primary antibody (Clone EA-53; Sigma, St. Louis, MO) diluted at 1:3,000 in 5\% milk TBS- $T$ was added and membranes were incubated for 1 hour at room temperature.

- Membranes were washed $(3 \times)$ for 10 minutes each in PBS-T.

- Secondary antibodies compatible with the laboratories' imaging equipment were used, e.g., horseradish peroxidaseconjugated goat anti-rabbit $(1: 15,000)$ and goat anti-mouse $\operatorname{IgG}(1: 500,000)$ were incubated with the membranes for 30 minutes at room temperature.

- Membranes were washed $(3 \times)$ for 10 minutes each in TBS-T.

Each laboratory used their preferred image acquisition equipment (e.g., Image J-based software, Odyssey infrared imaging system); the data were normalized to $\alpha$-actinin and presented relative to an average of the 2 controls.

Statistical analysis. Experiments were performed in triplicate and statistical analysis was performed using GraphPad Prism version 5.03 (GraphPad Software, La Jolla, CA). The coefficient of variation $(\mathrm{CV})$ was calculated using the formula $\mathrm{CV}=\mathrm{SD} /$ mean $\times 100$. For intralaboratory analysis, the CV for each laboratory for each biopsy was calculated (tables e-1 to e- 6 ) and the $\mathrm{CV}$ s from the 6 biopsies were averaged for each laboratory.

The Bland-Altman plot was used to assess the agreement between different methods. ${ }^{21}$

RESULTS Each laboratory ranked the samples according to the relative level of dystrophin expression determined by each technique (table 1). There was a high level of agreement among all laboratories for both immunohistochemistry and Western blotting. All laboratories identified the $3 \mathrm{BMD}$ samples as having the highest dystrophin protein levels, although this top order differed between immunohistochemistry and Western blotting. By Western blot analysis, no laboratory could detect dystrophin in sample B and only 2 laboratories (3 and 4) could detect trace amounts of dystrophin protein in sample E.

Inter- and intralaboratory variability of dystrophin quantification using immunohistochemistry. From each laboratory's data (Arechavala-Gomeza ${ }^{19}$ method), we calculated the mean $( \pm S D)$ dystrophin levels of each sample and the CV (figure 1). Overall, the level of variability observed among the different laboratories was minimal with an average SD of 7.78 (ranging between 3.33 for sample $E$ and 11.93 for sample A). We calculated the $\mathrm{CV}$ for each sample to statistically measure the degree of variation between the laboratories. A CV value of less than

Figure 1 Inter- and intralaboratory variability of dystrophin quantification using immunohistochemistry
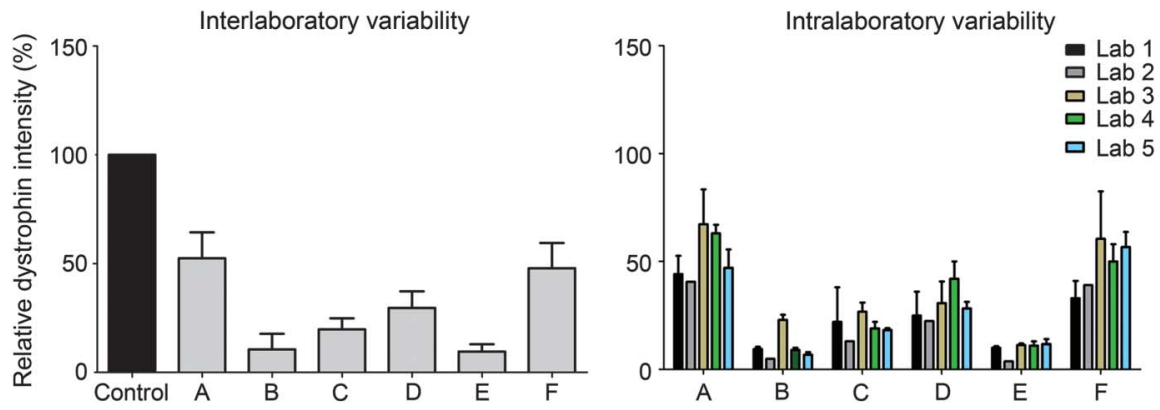

\begin{tabular}{c|ccc|c|c}
\hline \multicolumn{4}{c|}{ Interlaboratory variability } & \multicolumn{2}{c}{ Intralaboratory variability } \\
Sample & $\mathrm{n}$ & Mean \pm SD & CV & Lab & Average CV \\
\cline { 2 - 6 } A & 5 & $52.42 \pm 11.93$ & 22.76 & 1 & 29.83 \\
B & 5 & $10.6 \pm 7.13$ & 67.26 & 2 & n/a \\
C & 5 & $19.79 \pm 5.04$ & 25.47 & 3 & 20.9 \\
D & 5 & $29.64 \pm 7.6$ & 25.64 & 4 & 14.41 \\
E & 5 & $9.56 \pm 3.33$ & 34.83 & 5 & 13.71 \\
F & 5 & $47.85 \pm 11.65$ & 24.35 & - & - \\
\hline
\end{tabular}

Five laboratories each quantified the level of dystrophin expression in the same 6 biopsies using a standardized immunohistochemistry protocol; data were analyzed using the Arechavala-Gomeza method. ${ }^{19}$ To assess interlaboratory variability, the mean \pm SD for each biopsy was calculated as well as the coefficient of variation (CV). Note how this variation is higher for those samples containing less dystrophin ( $E$ and B). To assess intraassay precision within each laboratory, the mean \pm SD for each laboratory per sample was calculated as well as the average CV per laboratory. Laboratories are unidentified. 
$20 \%$ is considered optimal. ${ }^{22}$ The CV values averaged $33 \%$ (ranging between 23\% for sample A and 67\% for sample B); samples A, C, D, and F had CV values between $20 \%$ and $30 \%$.

We next analyzed intralaboratory variability in the same manner (figure 1). We calculated the average $\mathrm{CV}$ value from each laboratory (see tables e-1 to e-6 for individual data). The CV values for immunohistochemistry were below 30\% for all laboratories, with laboratories 4 and 5 having low CV values of $14 \%$ and $14 \%$, respectively.

\section{Figure 2 Assessing the agreement between different methods of} immunohistochemical dystrophin measurement
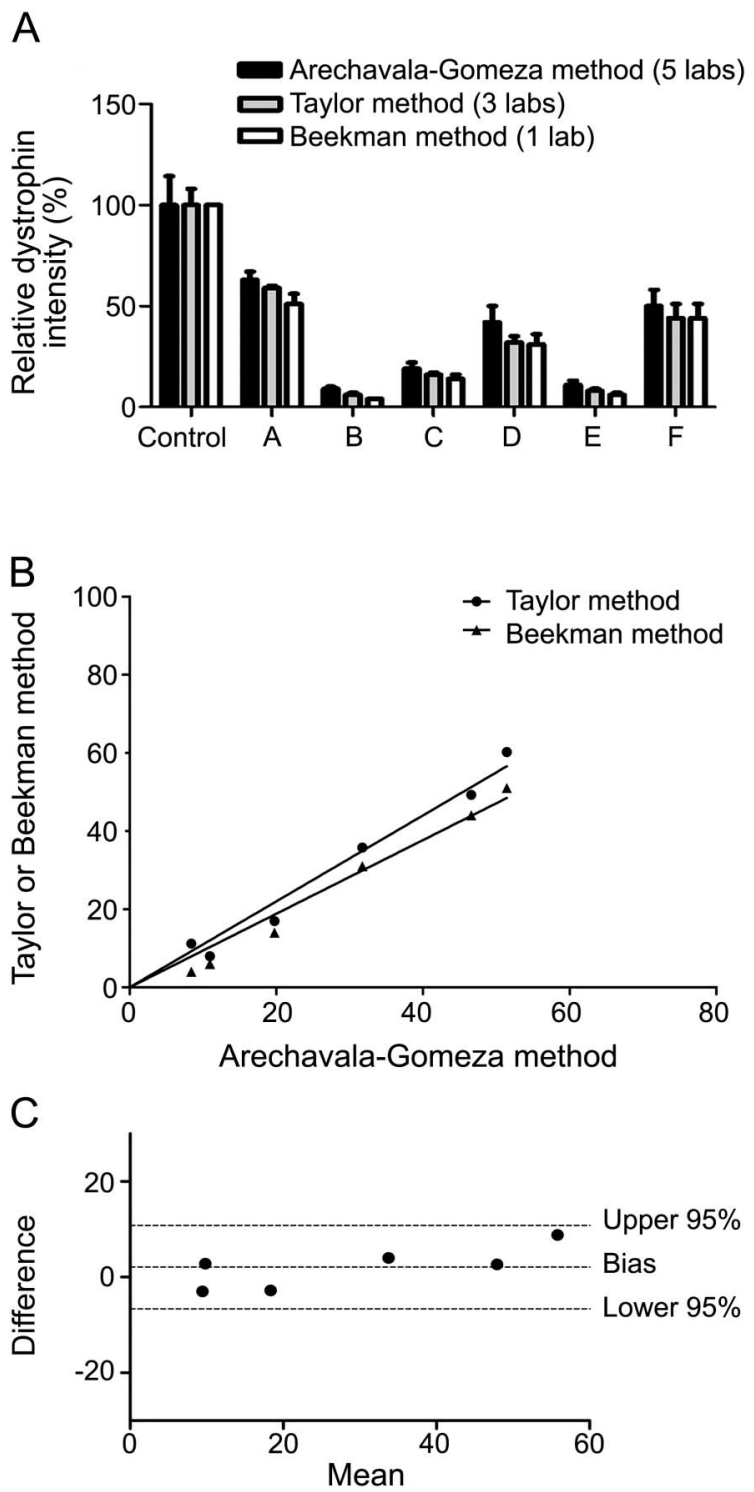

The mean data from each method were compared in a bar chart \pm SD (A) and plotted with a regression line $(B)$. The difference between the Arechavala-Gomeza and Taylor methods was plotted against their mean in a Bland-Altman plot (C) where the mean of the differences between the methods represents the bias (i.e., the value determined by one method minus the value determined by the other method) and the upper and lower $95 \%$ confidence limits represent the upper and lower limits of agreement, respectively (the difference between the 2 methods should lie within these bounds on $95 \%$ of occasions).
While all laboratories were able to use the Arechavala-Gomeza method, ${ }^{19}$ some laboratories had access to software that enabled them to directly compare this method with additional automated methods. Three laboratories (1, 4, and 5) analyzed the same samples using the Taylor method and one laboratory (4) compared 3 different methods (Arechavala-Gomeza, ${ }^{19}$ Taylor, ${ }^{18}$ and Beekman ${ }^{20}$ methods). We analyzed the same images using the above intensity measurement techniques and we assessed the level of agreement between them by plotting the mean $( \pm S D)$ of each sample for all techniques (figure 2A). Next, rather than calculate the correlation coefficient, which can hide a considerable lack of agreement, ${ }^{23}$ we plotted the data with a regression line, plotting the more automated Taylor ${ }^{18}$ or Beekman ${ }^{20}$ methods against the Arechavala-Gomeza ${ }^{19}$ method (figure 2B). We then selected the 2 methods used by more than one laboratory (Arechavala-Gomeza ${ }^{19}$ and Taylor ${ }^{18}$ methods), observed that the mean data from the 2 techniques were essentially identical (figure 2, A and $\mathrm{B}$ ), and generated a Bland-Altman plot (figure 2C). ${ }^{23}$ This analysis shows that both methods are equivalent: the bias (the difference between the means) was only 2.103 and the $95 \%$ limits of agreement were between 10.83 and -6.63 .

Inter- and intralaboratory variability of dystrophin quantification using Western blotting. We assessed the level of inter- and intralaboratory variability observed with Western blotting as above (figure 3). We observed more variability with Western blotting than immunohistochemistry with a mean SD of 15.95 (ranging between 0.89 for sample E and 33.09 for sample F). The CV values for Western blotting averaged $80 \%$ (ranging between $23 \%$ for sample $\mathrm{F}$ and $223 \%$ for sample E) confirming a higher degree of variability with this technique; only samples $\mathrm{D}$ and $\mathrm{F}$ had CV values nearing 20\% (figure 3). The CV values were particularly affected by 2 of the samples (B and E) being at/below the limit of sensitivity; our results thus indicate that the interlaboratory variability improves as the level of dystrophin increases.

Intralaboratory variability was also more pronounced than for immunohistochemistry. Only laboratory 1 had an optimal $\mathrm{CV}$ value of $0.3 \%$; laboratory 3 had the highest at 119\% (figure 3).

Immunohistochemistry and Western blotting data comparison. To assess the level of agreement between the immunohistochemistry and Western blotting data, we plotted the mean $( \pm S D)$ of each sample for both techniques (figure 4A), plotted the data with a regression line (figure $4 \mathrm{~B}$ ), and generated a BlandAltman plot of the difference between the methods against their mean (figure 4C). ${ }^{23}$ The level of bias was -14.18 and the upper and lower limits of agreement 

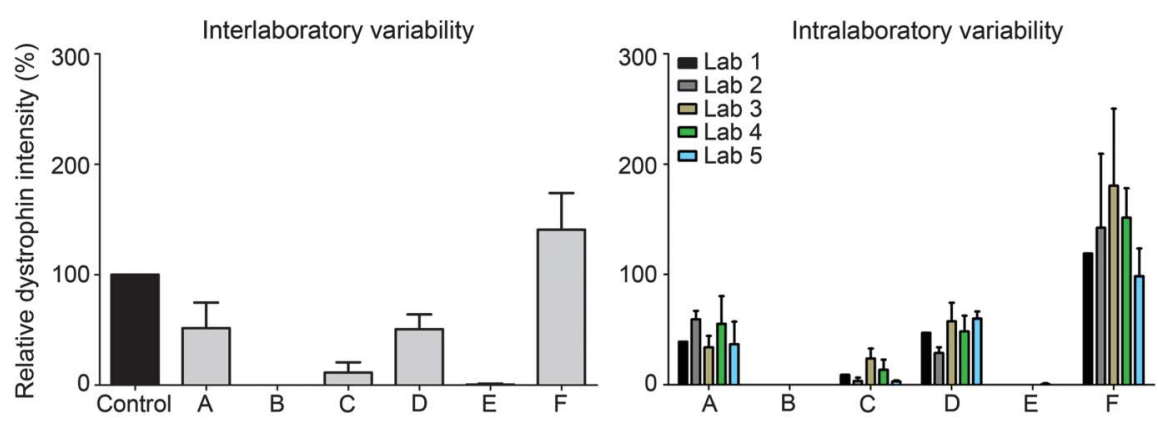

\begin{tabular}{|c|c|c|c|c|c|}
\hline \multicolumn{4}{|c|}{ Interlaboratory variability } & \multicolumn{2}{|c|}{ Intralaboratory variability } \\
\hline Sample & $\mathrm{n}$ & Mean \pm SD & $\mathrm{CV}$ & Lab & Average CV \\
\hline A & 5 & $51.62 \pm 23.17$ & 44.89 & 1 & 0.3 \\
\hline$B$ & 5 & $0 \pm 0$ & $\mathrm{n} / \mathrm{a}$ & 2 & 37.76 \\
\hline C & 5 & $11.41 \pm 9.22$ & 80.81 & 3 & 118.88 \\
\hline $\mathrm{D}$ & 5 & $50.67 \pm 13.39$ & 26.43 & 4 & 86.86 \\
\hline$E$ & 5 & $0.4 \pm 0.89$ & 222.5 & 5 & 32.98 \\
\hline $\mathrm{F}$ & 5 & $140.85 \pm 33.09$ & 23.49 & - & - \\
\hline
\end{tabular}

Five laboratories each quantified the level of dystrophin expression in the same 6 biopsies using a standardized Western blotting protocol. To assess interlaboratory variability, the mean \pm SD for each laboratory and biopsy was plotted on a bar chart and the average coefficient of variation (CV) per laboratory calculated. To assess intralaboratory variation, the mean \pm SD for each laboratory per sample was calculated as well as the average CV per laboratory. Laboratories are unidentified.

were 64.96 and -93.32 , respectively. Although our sample size is small, the scatter of data points in figure $4 \mathrm{C}$ suggests that as the mean increases, the difference between the 2 methods also increases. Thus, while the immunohistochemistry and Western blotting data are somewhat comparable, the data are not in perfect agreement; this is unlikely to be attributable to technical problems but rather to the different properties of mutant dystrophin. For example, there is a large discrepancy for sample F (patient with BMD with a deletion of exons 10-44) with which the level of dystrophin quantified by Western blotting is considerably higher than that determined by immunohistochemistry (see discussion).

DISCUSSION Dystrophin expression is being used as a secondary outcome measure in several clinical trials, but the lack of standardized procedures limits the ability to compare these different studies.

We set up a study in which we first standardized the methodologies for detecting dystrophin expression and then applied them to assess patients with DMD and BMD. Our data show that optimized immunohistochemistry and Western blotting were surprisingly concordant given the variable nature of dystrophinopathy biopsies (e.g., variable fibro-fatty replacement between biopsies and variable dystrophin content within serial sections of the same biopsy). We demonstrated that properly handled tissue can be distributed to multiple centers internationally to achieve comparable results. Because recent studies demonstrated that dystrophin expression can vary between different controls, we distributed control biopsies to each laboratory. ${ }^{19}$ In the context of clinical trials, this is a variable that will need to be considered, either by using one set of control samples, which may not be realistic, or the use of humanized mouse muscle. ${ }^{24,25}$ In any case in a clinical trial, the use of each patient's pre- or nontreated muscle biopsy is of paramount importance because of the variable levels of revertant fibers and trace dystrophin expression in each patient. ${ }^{15,16}$

Our study demonstrates that mean dystrophin levels obtained using 3 alternative immunohistochemical methods were comparable, suggesting that when the mean dystrophin level per biopsy is reported, the choice of which published script is used is not crucial, ${ }^{18-20}$ although extra information could be obtained with some approaches over others. ${ }^{26} \mathrm{We}$ have validated the robustness, in a multicentre setting, of the Arechavala-Gomeza ${ }^{19}$ (5 laboratories) and Taylor ${ }^{18}$ (3 laboratories) methods by evaluating the precision of results generated by different equipment and operators. The Beekman ${ }^{20}$ method was only tested in one of the participating laboratories. One limitation of this study was that the numbers of controls and test specimens were relatively small, because it is extremely challenging to obtain human muscle biopsies of the size needed for such a comparative study. 
Figure 4 Assessing the agreement between immunohistochemistry and Western blotting for dystrophin quantification
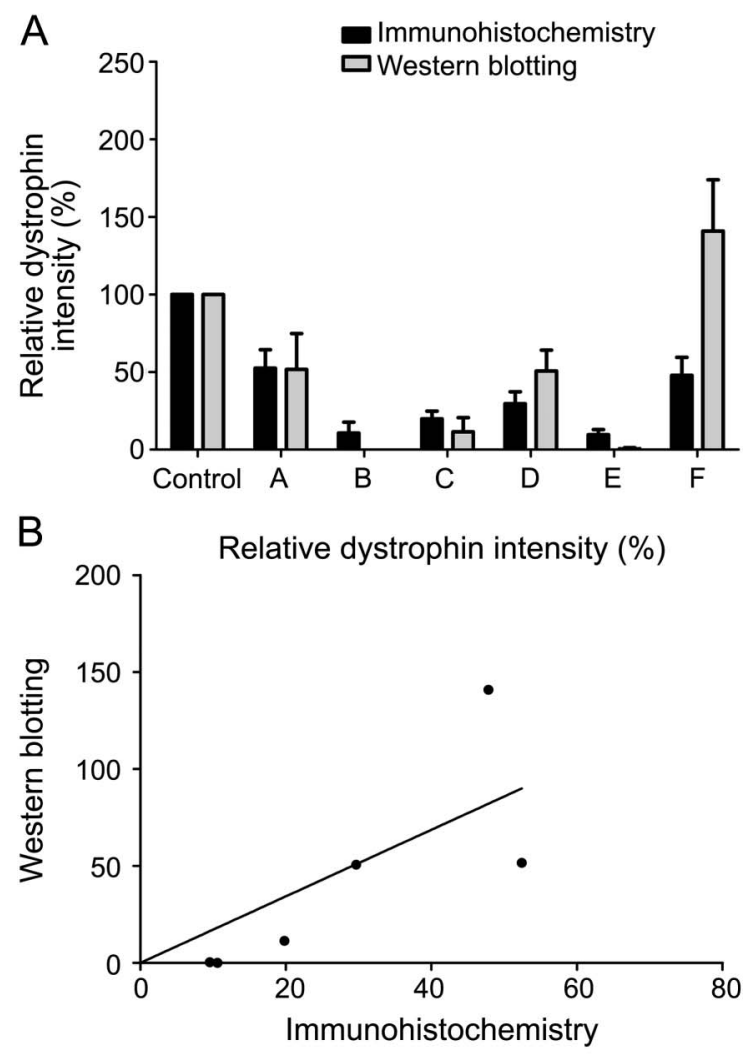

C

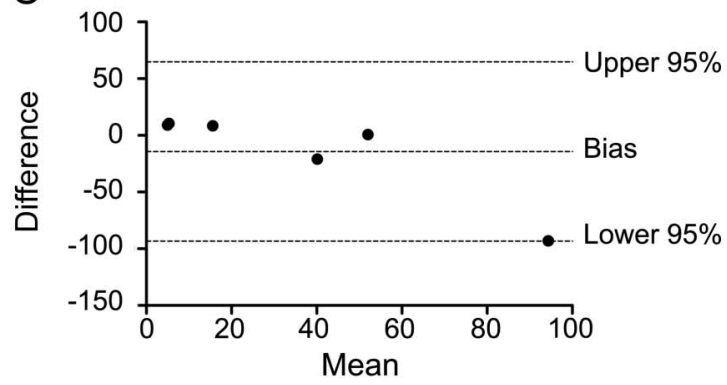

The mean immunohistochemistry and Western blotting data for each biopsy were compared in a bar chart \pm SD (A) and plotted with a regression line (B). The difference between the methods was plotted against their mean in a Bland-Altman plot (C) where the mean of the differences between the methods represents the bias (i.e., the value determined by one method minus the value determined by the other method) and the upper and lower $95 \%$ confidence limits represent the upper and lower limits of agreement, respectively (the difference between the 2 methods should lie within these bounds on $95 \%$ of occasions).

Immunohistochemistry and Western blotting (measuring sarcolemmal and total dystrophin, respectively) give information that is not necessarily identical, but rather complementary, especially in diseased muscle. For example, in some samples (e.g., BMD sample A, c.40_41delGA), the level of dystrophin determined by both techniques was highly comparable, while with others (e.g., BMD sample F, del ex 10-44), the level of dystrophin quantified by Western blotting was significantly higher than that determined by immunohistochemistry. Considering that this patient carries a large deletion removing a significant portion of the actin-binding domain, ${ }^{27,28}$ and the ability of this mutant dystrophin to bind to the sarcolemma, we suggest that Western blotting in this case overestimates the amount of functional dystrophin. Similar findings have been reported in transgenic $m d x$ mice carrying BMD-like molecules, in which lower levels of mini-dystrophin were observed in the sarcolemmal Western blot fractions compared with mice expressing full-length dystrophin. ${ }^{29}$ Considering that many BMD mutations (and the equivalent DMD mutations after exon skipping) affect the 3-dimensional structure and actin-binding properties of dystrophin, ${ }^{30-32}$ capturing both the total amount of dystrophin in the homogenate as well as its localization at the sarcolemma is clearly important. Assessing dystrophin using immunohistochemistry is also important, because a different pattern of expression can lead to differences in the functional outcome irrespective of the total amount of protein present. For example, in transgenic $m d x$ mice, mice with a low, but uniform dystrophin expression have a milder phenotype than $m d x$ mice with a higher, but variable pattern. ${ }^{33}$

Immunohistochemistry and Western blotting are not necessarily the most novel methods for dystrophin quantification but they remain widely available and accessible. Alternative, but less widely available techniques, such as mass spectrometry ${ }^{34}$ and ELISA, may be advantageous for detecting linear increments of dystrophin from very small amounts of sample. However, their use in isolation would not be desirable because of the issues related to the functionality and localization of mutant dystrophin discussed above. Based on the results of our study, we recommend that dystrophin restoration in clinical trials should be quantified using parallel techniques, which are, in hierarchy of importance: (1) sarcolemmal dystrophin quantification by immunohistochemistry, and (2) quantitative Western blotting or alternative techniques measuring total dystrophin levels in muscle homogenates such as mass spectrometry. Counting dystrophin-positive fibers is also used, but interlaboratory reliability has not been assessed; it currently relies on a qualitative rather than quantitative operational definition for "positive fibers." Nevertheless, within a single laboratory, the reproducibility of counting dystrophin-positive fibers has been indicated, although the use of a pretreatment threshold is paramount. ${ }^{7,9}$

Our study demonstrates that when biopsy preparation and antibody protocols are standardized, multiple laboratories are able to reliably measure dystrophin expression using existing techniques. We therefore recommend the use of standardized immunohistochemical and Western blotting methods in parallel as robust biochemical outcome measures for DMD clinical trials. 


\section{AUTHOR CONTRIBUTIONS}

Karen Anthony: drafting/revising the manuscript for content, study concept or design, analysis or interpretation of data, acquisition of data, statistical analysis, and study coordination. Virginia Arechavala-Gomeza: drafting/revising the manuscript for content, study concept or design, analysis or interpretation of data, acquisition of data, and study coordination. Laura E. Taylor: study concept or design, contribution of vital reagents/tools/patents, and study supervision or coordination. Adeline Vulin: analysis or interpretation of data and acquisition of data. Yuuki Kaminoh: analysis or interpretation of data, acquisition of data, statistical analysis. Silvia Torelli: analysis or interpretation of data, acquisition of data, drafting/revising the manuscript for content. Lucy Feng: drafting/ revising the manuscript for content, including medical writing for content, and contribution of vital reagents/tools/patents. Narinder Janghra: analysis or interpretation of data, acquisition of data. Gisèle Bonne: analysis or interpretation of data and study supervision/coordination. Maud Beuvin: analysis or interpretation of data. Rita Barresi: revising the manuscript for content, acquisition of data. Matt Henderson: revising the manuscript for content, contribution of vital reagents/tools/patents and acquisition of data. Steven Laval: analysis or interpretation of data. Afrodite Lourbakos: drafting/revising the manuscript for content, including medical writing for content, study concept or design, and analysis or interpretation of data. Giles Campion: drafting/revising the manuscript for content, including medical writing for content, analysis or interpretation of data, and study supervision or coordination. Volker Straub: study concept or design, analysis or interpretation of data, acquisition of data, study supervision or coordination, and obtaining funding. Thomas Voit: study concept and design, interpretation of data, study supervision, and obtaining funding. Caroline Sewry: drafting/revising the manuscript for content. Jennifer Morgan: drafting/revising the manuscript for content, study concept or design, analysis or interpretation of data. Kevin M. Flanigan: drafting/revising the manuscript for content, including medical writing for content, study concept or design, analysis or interpretation of data, contribution of vital reagents/tools, acquisition of data, and study supervision/coordination. Francesco Muntoni: drafting/revising the manuscript for content, including medical writing for content, study concept or design, analysis or interpretation of data, study supervision or coordination, and obtaining funding.

\section{ACKNOWLEDGMENT}

The authors gratefully acknowledge Eric Hoffman, PhD (Children's National Medical Center, Washington, DC, additional member of the BOM-SG), Kristy Brown, PhD (Children's National Medical Center, Washington, DC, additional member of the BOM-SG), Heather Gordish-Dressman, PhD (Children's National Medical Center, Washington, DC, additional member of the BOM-SG), Alessandra Ferlini, MD, PhD (University of Ferrara, Italy, additional member of the BOM-SG), Steven Moore, MD, PhD (University of Iowa, additional member of the BOM-SG), Diane Frank, PhD (Sarepta Therapeutics, additional member of the BOM-SG), Ellen Welch, PhD (PTC Therapeutics, additional member of the BOM-SG), Darren Chambers (University College London, technical help), and Deborah Ridout (University College London, statistical help).

\section{STUDY FUNDING}

The research leading to these results has received funding from the following grant-giving bodies: European Union's seventh framework programme (FP7/2007-2013) under SKIP-NMD grant agreement number 305370; Association Française contre les Myopathies (AFM) and Wellcome Trust grant HICF-1009-025 to F.M. The authors acknowledge the support of the TREAT-NMD Neuromuscular Network. F.M. is supported by the Great Ormond Street Hospital Children's Charity and the National Institute for Health Research Biomedical Research Centre at Great Ormond Street Hospital for Children NHS Foundation Trust and University College London. J.E.M. was supported by a Wellcome Trust University Award and is currently supported by the Great Ormond Street Hospital Children's Charity. K.M.F. is supported by the National Institute of Neurological Diseases and Stroke (R01 NS043264) and CureDuchenne. Diagnostic facilities at the Newcastle Muscle Centre are supported by the Rare Diseases Advisory Group service for Neuromuscular Diseases (NHS England).

\section{DISCLOSURE}

K. Anthony reports research support from the Association Française Myopathies (AFM) during the conduct of the study. V. Arechavala-Gomeza, L. Taylor, A. Vulin, Y. Kaminoh, S. Torelli, L. Feng, N. Janghra, G. Bonne, M. Beuvin, R. Barresi, M. Henderson, and S. Laval report no disclosures relevant to the manuscript. A. Lourbakos is an employee of Prosensa, which includes participation in stock-option plans. G. Campion is an employee of Prosensa Holdings NV and holds company stock. V. Straub received honoraria from serving on the Scientific Advisory Boards for Pfizer and for Genzyme/Sanofi. He serves as an editorial board member of Neuromuscular Disorders, Journal of Neuromuscular Diseases, and Neuropädiatrie in Klinik und Praxis. He received research support from the Association Française contre les Myopathies, the Sylvia Aitken Charitable Trust, Action Medical Research, the European Commission, the Medical Research Council, Parent Project Muscular Dystrophy, the Muscular Dystrophy AssociationUSA, and the LGMD2I Research Fund. T. Voit reports being a SAB member of PROSENSA and DART, inventor on 8 patents, associate editor for Neuromuscular Disorders, a PI on 3 ongoing clinical trials (PTC, PROSENSA), and receiving academic research support from EU FP 7 SKIP-NMD, SCOPE-DMD, and BIOIMAGE-NMD. C. Sewry reports royalties from 2 books-publishers Elsevier and Wiley-Backwell; she is also a member of the editorial board of Neuromuscular Disorders and Muscle \& Nerve and executive editor of Neuropathology and Applied Neurobiology. J. Morgan reports no disclosures relevant to the manuscript. K. Flanigan has served as a site investigator for studies funded by GSK, PTC Therapeutics, Halo Therapeutics, and Prosensa Therapeutics; on advisory boards for Sarepta Therapeutics; and as a consultant to Eli Lilly. He has received research funding from the NIH, Parent Project Muscular Dystrophy, and CureDuchenne and is a member of the editorial board of Neuromuscular Disorders. F. Muntoni has served on scientific advisory boards for Roche, PTC, Summit, Italfarmaco, and Sarepta Therapeutics; he serves on the scientific advisory board for Pfizer and the editorial board of Neuromuscular Disorders and Neuropediatrics; his institution (UCL) receives research support from the European Union, the Medical Research Council, the Wellcome Trust, the Association Française contre les Myopathies (AFM), the Muscular Dystrophy Campaign, the Great Ormond Street Hospital (GOSH) Biomedical Research Centre, GSK, Genethon, and NIH. His institutions (UCL and GOSH) receive funding for clinical trials from GSK, Trophos, Prosensa, the British Heart Foundation, Summit, and has received funding for trials from AVI BioPharma and PTC Therapeutics. Go to Neurology.org for full disclosures.

Received March 14, 2014. Accepted in final form September 2, 2014.

\section{REFERENCES}

1. Abbs S, Tuffery-Giraud S, Bakker E, Ferlini A, Sejersen T, Mueller CR. Best practice guidelines on molecular diagnostics in Duchenne/Becker muscular dystrophies. Neuromuscul Disord 2010;20:422-427.

2. Muntoni F, Torelli S, Ferlini A. Dystrophin and mutations: one gene, several proteins, multiple phenotypes. Lancet Neurol 2003;2:731-740.

3. Bushby KM, Gardner-Medwin D, Nicholson LV, et al. The clinical, genetic and dystrophin characteristics of Becker muscular dystrophy: II: correlation of phenotype with genetic and protein abnormalities. J Neurol 1993;240:105-112.

4. Bushby KM, Gardner-Medwin D. The clinical, genetic and dystrophin characteristics of Becker muscular dystrophy: I: natural history. J Neurol 1993;240:98-104.

5. Chelly J, Gilgenkrantz H, Lambert M, et al. Effect of dystrophin gene deletions on mRNA levels and processing in Duchenne and Becker muscular dystrophies. Cell 1990; 63:1239-1248.

6. Goemans NM, Tulinius M, van den Akker JT, et al. Systemic administration of PRO051 in Duchenne's muscular dystrophy. N Engl J Med 2011;364:1513-1522. 
7. Kinali M, Arechavala-Gomeza V, Feng L, et al. Local restoration of dystrophin expression with the morpholino oligomer AVI-4658 in Duchenne muscular dystrophy: a single-blind, placebo-controlled, dose-escalation, proof-ofconcept study. Lancet Neurol 2009;8:918-928.

8. Arechavala-Gomeza V, Anthony K, Morgan J, Muntoni F. Antisense oligonucleotide-mediated exon skipping for Duchenne muscular dystrophy: progress and challenges. Curr Gene Ther 2012;12:152-160.

9. Cirak S, Arechavala-Gomeza V, Guglieri M, et al. Exon skipping and dystrophin restoration in patients with Duchenne muscular dystrophy after systemic phosphorodiamidate morpholino oligomer treatment: an open-label, phase 2, dose-escalation study. Lancet 2011;378:595-605.

10. Cirak S, Feng L, Anthony K, et al. Restoration of the dystrophin-associated glycoprotein complex after exon skipping therapy in Duchenne muscular dystrophy. Mol Ther 2012;20:462-467.

11. Mendell JR, Rodino-Klapac LR, Sahenk Z, et al. Eteplirsen for the treatment of Duchenne muscular dystrophy. Ann Neurol 2013;74:637-647.

12. Hirawat S, Welch EM, Elfring GL, et al. Safety, tolerability, and pharmacokinetics of PTC124, a nonaminoglycoside nonsense mutation suppressor, following single- and multiple-dose administration to healthy male and female adult volunteers. J Clin Pharmacol 2007;47:430-444.

13. Welch EM, Barton ER, Zhuo J, et al. PTC124 targets genetic disorders caused by nonsense mutations. Nature 2007;447:87-91.

14. Mendell JR, Campbell K, Rodino-Klapac L, et al. Dystrophin immunity in Duchenne's muscular dystrophy. N Engl J Med 2010;363:1429-1437.

15. Arechavala-Gomeza V, Kinali M, Feng L, et al. Revertant fibres and dystrophin traces in Duchenne muscular dystrophy: implication for clinical trials. Neuromuscul Disord 2010;20:295-301.

16. Lourbakos A, Sipkens J, Beekman C, et al. The incidence of revertant and trace dystrophin expression in muscle biopsies of Duchenne muscular dystrophy patients with different exon deletions. Neuromuscul Disord 2011;21:643.

17. Muntoni F; Meeting Steering Committee and TREATNMD Network. The development of antisense oligonucleotide therapies for Duchenne muscular dystrophy: report on a TREAT-NMD workshop hosted by the European Medicines Agency (EMA), on September 25th 2009. Neuromuscul Disord 2010;20:355-362.

18. Taylor LE, Kaminoh YJ, Rodesch CK, Flanigan KM. Quantification of dystrophin immunofluorescence in dystrophinopathy muscle specimens. Neuropathol Appl Neurobiol 2012;38:591-601.

19. Arechavala-Gomeza V, Kinali M, Feng L, et al. Immunohistological intensity measurements as a tool to assess sarcolemma-associated protein expression. Neuropathol Appl Neurobiol 2010;36:265-274.

20. Beekman C, Sipkens JA, Testerink J, et al. A sensitive, reproducible and objective immunofluorescence analysis method of dystrophin in individual fibers in samples from patients with Duchenne muscular dystrophy. PLoS One 2014;9:e107494.

21. Altman DG, Bland JM. Measurement in medicine: the analysis of method comparison studies. Statistician 1983; 32:307-317.

22. European Medicines Agency. Guideline on bioanalytical method validation. Available at: http://www.ema.europa.eu/ docs/en_GB/document_library/Scientific_guideline/2011/08/ WC500109686.pdf. Accessed October 16, 2014.

23. Bland JM, Altman DG. Statistical methods for assessing agreement between two methods of clinical measurement. Lancet 1986;1:307-310.

24. Bremmer-Bout M, Aartsma-Rus A, de Meijer EJ, et al. Targeted exon skipping in transgenic hDMD mice: a model for direct preclinical screening of humanspecific antisense oligonucleotides. Mol Ther 2004;10: 232-240.

25. 't Hoen PA, de Meijer EJ, Boer JM, et al. Generation and characterization of transgenic mice with the full-length human DMD gene. J Biol Chem 2008;283:5899-5907.

26. Arechavala-Gomeza V, Feng L, Morgan JE, Muntoni F. Correspondence: measuring dystrophin—faster is not necessarily better. Nat Rev Neurol 2012;8:469.

27. Ervasti JM, Campbell KP. A role for the dystrophinglycoprotein complex as a transmembrane linker between laminin and actin. J Cell Biol 1993;122:809-823.

28. Vulin A, Wein N, Strandjord DM, et al. The ZZ domain of dystrophin in DMD: making sense of missense mutations. Hum Mutat 2014;35:257-264.

29. Wells DJ, Wells KE, Asante EA, et al. Expression of human full-length and minidystrophin in transgenic $\mathrm{mdx}$ mice: implications for gene therapy of Duchenne muscular dystrophy. Hum Mol Genet 1995;4:1245-1250.

30. Ervasti JM. Dystrophin, its interactions with other proteins, and implications for muscular dystrophy. Biochim Biophys Acta 2007;1772:108-117.

31. Henderson DM, Lin AY, Thomas DD, Ervasti JM. The carboxy-terminal third of dystrophin enhances actin binding activity. J Mol Biol 2012;416:414-424.

32. Henderson DM, Belanto JJ, Li B, Heun-Johnson H, Ervasti JM. Internal deletion compromises the stability of dystrophin. Hum Mol Genet 2011;20:2955-2963.

33. Phelps SF, Hauser MA, Cole NM, et al. Expression of fulllength and truncated dystrophin mini-genes in transgenic mdx mice. Hum Mol Genet 1995;4:1251-1258.

34. Brown KJ, Marathi R, Fiorillo AA, et al. Accurate quantitation of dystrophin protein in human skeletal muscle using mass spectrometry. J Bioanal Biomed 2012;(suppl 7):001. 


\section{Neurology}

\section{Dystrophin quantification: Biological and translational research implications}

Karen Anthony, Virginia Arechavala-Gomeza, Laura E. Taylor, et al.

Neurology 2014;83;2062-2069 Published Online before print October 29, 2014

DOI 10.1212/WNL.0000000000001025

\section{This information is current as of October 29, 2014}

$\begin{array}{ll}\begin{array}{l}\text { Updated Information \& } \\ \text { Services }\end{array} & \begin{array}{l}\text { including high resolution figures, can be found at: } \\ \text { http://n.neurology.org/content/83/22/2062.full }\end{array} \\ \text { Supplementary Material } & \text { Supplementary material can be found at: } \\ \text { http://n.neurology.org/content/suppl/2014/10/29/WNL.0000000000001 } & 025 . D C 1 \\ & \text { This article cites } 32 \text { articles, } 2 \text { of which you can access for free at: } \\ & \text { http://n.neurology.org/content/83/22/2062.full\#ref-list-1 } \\ \text { References } & \text { This article, along with others on similar topics, appears in the } \\ & \text { following collection(s): } \\ \text { All Clinical trials } & \text { http://n.neurology.org/cgi/collection/all_clinical_trials } \\ \text { Mubspecialty Collections } & \text { Muscle disease } \\ & \text { http://n.neurology.org/cgi/collection/muscle_disease } \\ \text { Outtome research } & \text { http://n.neurology.org/cgi/collection/outcome_research } \\ & \text { Information about reproducing this article in parts (figures,tables) or in } \\ & \text { its entirety can be found online at: } \\ & \text { http://www.neurology.org/about/about_the_journal\#permissions } \\ \text { Permissions \& Licensing } & \text { Information about ordering reprints can be found online: } \\ & \text { http://n.neurology.org/subscribers/advertise }\end{array}$

Neurology ${ }^{\circledR}$ is the official journal of the American Academy of Neurology. Published continuously since 1951, it is now a weekly with 48 issues per year. Copyright () 2014 American Academy of Neurology. All rights reserved. Print ISSN: 0028-3878. Online ISSN: 1526-632X.

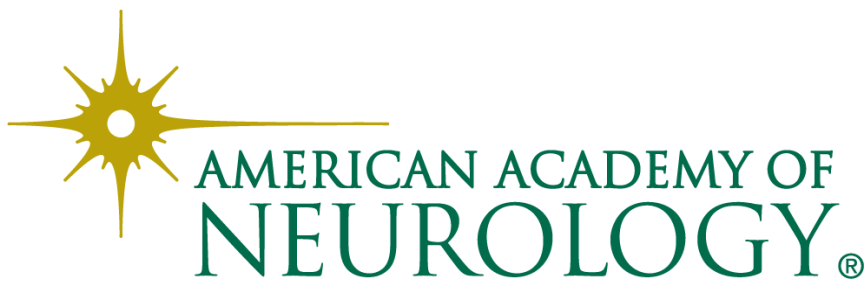

